\title{
Analgesic efficacy of caudal dexamethasone combined with bupivacaine in ilioinguinal pediatric surgery: prospective randomized controlled trial.
}

\author{
Hedi Chaker University Hospital , Sfax - TUNISIA
}

\section{Introduction :}

The epidural administration of dexamethasone was recently used in adults to reduce postoperative pain and analgesics request. In pediatric surgery, caudal block is commonly used with several adjuncts like sufentanil or clonidine . However, the analgesic effect of caudal dexamethasone is still under evaluation in children [5]. We designed this prospective, randomized, double-blind study to assess the efficacy of caudal dexamethasone on pain relief in children undergoing a day-case sub-umbilical surgical procedure.

\section{Material and methods}

After obtaining the Hedi Chaker university hospital (Tunisia) ethics committee approval and informed written consent from parents, 56 ASA I class patients aged from 1 to 5 years, scheduled for sub-umblical surgical procedures were enrolled in this prospective randomized double blinded controlled trial.

General anesthesia was standardized in both groups. The caudal injection was done by preprepared $20 \mathrm{ml}$ syringes labeled "study".

We injected $1 \mathrm{ml} / \mathrm{kg}$ of this pre-prepared solution caudally for each patient enrolled in this study. Patient was turned supine after administration of the drug. The anesthetist and nurses in-charge of the patient were completely blinded to the content of syringes.

Patients were randomized into 2 groups

They were randomly allocated into one of the 2 groups.

Group I : received bupivacaine $2.5 \mathrm{mg} / \mathrm{kg}$ with placebo

Group II: received bupivacaine $2.5 \mathrm{mg} / \mathrm{kg}$ with dexamethasone $0.1 \mathrm{mg} / \mathrm{kg}$.

An increase of HR or MAP more than $20 \%$ comparing to baseline values, 15 min after administration of caudal anesthesia was considered as failure of caudal anesthesia and in this case, an intravenous dose of Alfentanyl $(20 \mu \mathrm{g} / \mathrm{Kg})$ was administrated. Patients, in whom caudal anesthesia failed, were excluded from the study

Pain was assessed by using CHEOPS Score [9] at the admission in the PACU $(\mathrm{H} 0)$, at the first $(\mathrm{H} 1)$, the second $(\mathrm{H} 2)$, the fourth $(\mathrm{H} 4)$, the sixth $(\mathrm{H} 6)$, the $12^{\text {th }}(\mathrm{H} 12)$ and the $24^{\text {th }}(\mathrm{H} 24)$ post operative hours. CHEOPS at $\mathrm{H} 12$ and $\mathrm{H} 24$ was assessed by phone because patients leaved the PACU at $\mathrm{H} 6$ as it was a day case surgical procedure. In the PACU, if patients had CHEOPS superior to 7, or if they requested, an additional analgesia was given
After the exit of PACU, all patients received $15 \mathrm{mg} / \mathrm{kg}$ of paracetamol orally 4 times a day. Oral ibuprofen was prescribed for analgesia after discharge. Children received $5 \mathrm{mg} \mathrm{kg}-1$ of ibuprofen for pain scores of 7or greater on CHEOPS.

We also looked for side effects

\section{Results}

In this study, 56 pediatric patients were included, 28 in each group. No case of caudal block failure was noted and no patient was excluded. No patient received alfentanil peroperatively.

Demographic data (age, weight, gender) and per operative data (duration of general anesthesia, duration of surgery and type of surgical procedure, mean blood pressure and

heart rate was comparable in the two groups (table 1).

For pain relief, CHEOPS was significantly higher in group II than group I from $\mathrm{H} 6$ to $\mathrm{H} 24$

No patient required additional analgesia during their stay in

PACU in both groups. However rescue doses of oral

Ibuprofen was seen in 16 patients in group I versus 3 patients in group II $(p<0.01)$. Time to the first administration of Ibuprofen recue dose was $7.6+/-1.1 \mathrm{~h}$ in group I versus $12.2+/-2.1$ in group II $(p<0.01)$

Side effects were similar in both groups. Nausea and vomiting was seen in 2 patients in group I versus no patient in group II. Motor blockade, respiratory depression and Pruritis were not seen in any patient of our study.

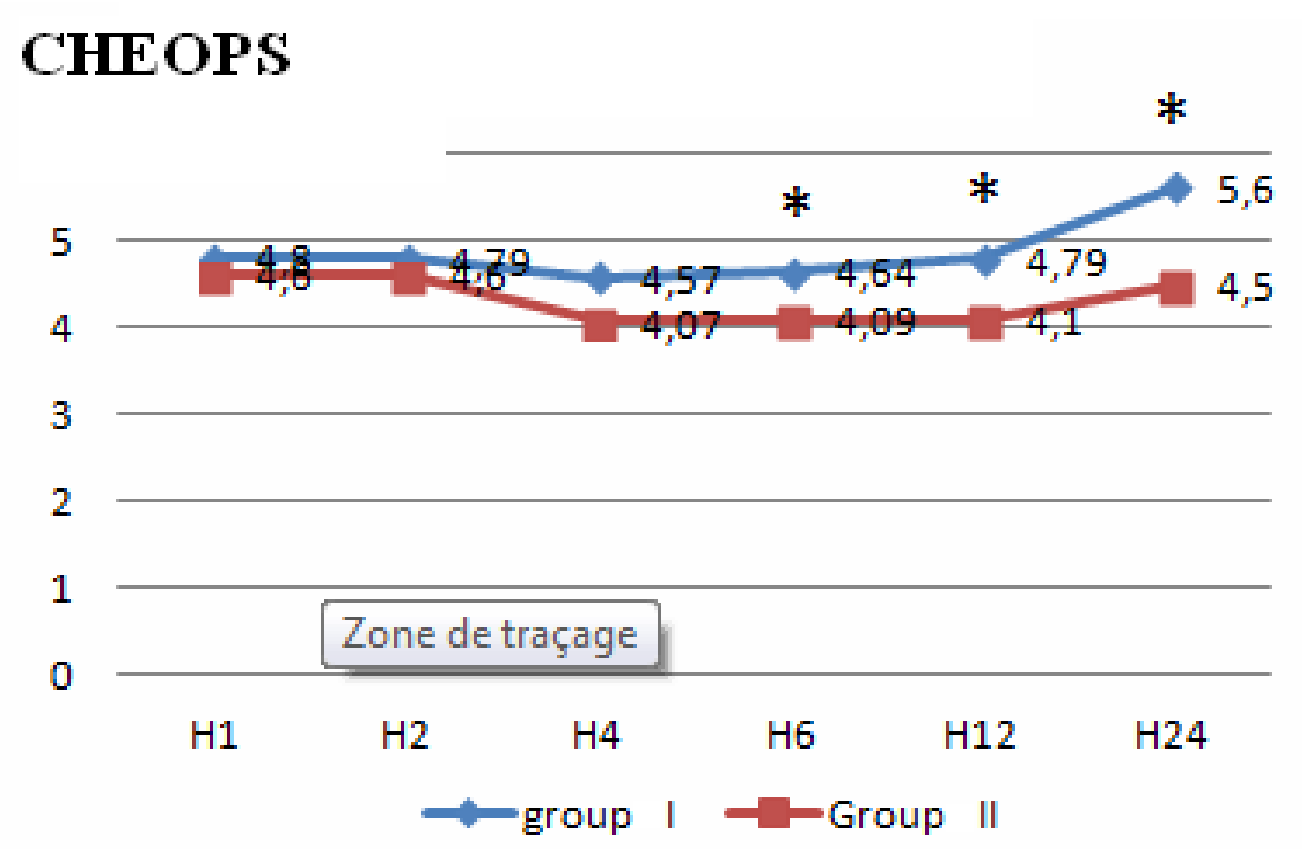

Discussion \& Conclusions:

Our results are suitable with previous studies in the litterature

Caudal dexamethasone may safely improve and prolongs post operative analgesia for sub-umblical surgical procedures in children. 